\title{
A patient's diary: episode 21 - Mrs Flagg reveals all (nearly)
}

My niece Emily gave me this diary for my birthday and told me I should write down the events of my daily life for the benefit of future generations. 'Yours must be a very interesting job, Auntie Ivy, she said, 'helping those glamorous doctors to save people's lives and sharing all their intimate moments. It must be just like The Practice on television.' Well, I couldn't help smiling to myself a little at that; young Emily has rather a romantic view of doctors and nurses, which is only natural in a girl of her age, bless her. I was just the same. But of course the reality of life at the surgery is not entirely a bed of roses by any means. Sick people can be very difficult to handle, especially when they have set their heart on something like an emergency appointment or a prescription for a drug of No Proven Value. And there are some I can think of, mentioning no names, who are not so ill as they make out, although it's not for me to judge of course. All I will say is, if I have an appointment left I'll give it to them, and if I haven't then they can always ring again tomorrow as soon as the phones open. And if they are not satisfied it's up to my doctors to decide.

Then of course, doctors themselves can be a bit of a handful at times. The general public likes to put them on a pedestal but behind the scenes they can behave like a lot of children stamping their feet and having tantrums. But I can handle them. I know them so well, you see, that's my secret. I was here in the days of old Dr Grimes, Dr Arthur's father. He was a real terror, I can tell you. Wouldn't stand any nonsense from anyone, but the patients were devoted to him. And Dr Teacher, I've known him since he came as a young lad, fresh from training. He had lots of new ideas for changing things, although that didn't last very long, I'm happy to say and he soon settled down. Then there's Dr Brenda Phillips, she's very easy to get on with, but then women are so much more sensible, aren't they? At first the patients thought it was strange having a woman doctor, you can hardly believe it can you? Now I don't know what we would do without her. She's so good with the children and a lot of the ladies will only see her especially for things that a man wouldn't understand even if he is a doctor. They tell me that more doctors are women than men these days and a good thing too! Mind you there have been so many changes round here since the old days I sometimes rub my eyes and wonder that I can still recognise the old place.

You see when I started with old Dr Grimes, there was just him and me and of course I used to do everything. Then young $\mathrm{Dr}$ Grimes came and then the other doctors. The practice grew and we had the extension built, what a carry on that was! We thought we had lots of space and now it feels cramped again, that's because there are so many receptionists now and we have a manager to be in charge of us. I wasn't too keen on that at first. They had to persuade me. I don't like the sound of it, Dr Grimes I said. If you and the other doctors are not satisfied with my work, I said then perhaps I should hand in my notice. No doubt your manager will be much younger and more the sort of person you want. Dear me, they said it's not like that at all, Mrs Flagg we all appreciate your devoted service to the practice, it's just that we feel you could use a little help. All the practices have managers nowadays. It will take a lot of the admin work off your shoulders and leave you free to concentrate on the patients.

Well I still had misgivings but I came round and agreed to stay. With the first manager I didn't see eye to eye over a number of things but fortunately she didn't stay too long. Nor did the second. But then we got Elena who is a very nice person and an excellent manager in my opinion. All the girls think so. We have lots of receptionists now, most of them very young and inexperienced but I soon get them trained.

And the nurses we have nowadays! They do health checks and cervical smears and talk to people on the phone who think they need an appointment when there aren't any left. They are practically doctors too.

As well as my three regular doctors and the two nurses, I generally have a trainee doctor. She comes for a year 'to learn the trade' as Dr Teacher puts it. Some of the patients are bit uncertain about an appointment with a new young doctor to begin with. They say, 'she looks very young, Mrs Flagg. I mean, no offence but does she know what she's doing? Suppose she gives me the wrong tablets?' I tell them that is very unlikely. $\mathrm{Dr}$ Greengage is ever so brainy and even if she did make a tiny mistake, I say, due to inexperience, you could always get them to wash your stomach out at the $\mathrm{A}$ and $\mathrm{E}$ department. This generally reassures them.

Most patients like to stick to one doctor when they can but with a popular one like $\mathrm{Dr}$ Brenda she can get booked up very quickly. And we don't have that many pre-booked appointments to give away, they are like gold dust. Now you might say, how can a person know in advance when they are going to need a doctor, and you'd have a point. But there do seem to be plenty of patients who can just sense that they are sickening for something. Take Norman Gland for instance. He has an appointment with Dr Brenda nearly every Thursday and he very rarely has to cancel. Of course he's quite happy to see someone else in an emergency - which happens about twice a week.

But it's not everyone who wants an appointment. A lot of people just come in for a prescription or a bit of advice from me. Of course, I'm not actually medically qualified but you can't do my job for however many years it is without learning a thing or two about illnesses. So if somebody wants to know a really good linctus or what to do for a tummy bug I can generally oblige. Some people ask me if they can have a repeat prescription for something they have not actually had for themselves but they have heard it did someone else a lot of good. Like Mrs Roundwell who's always trying to lose weight but lacks the will power. 'Can you put me down for some Slenderlites?' she pleads, 'and get one of the doctors to sign it?' Well, I can, but I have to be a bit careful because the doctors don't always notice what they are signing and it may not be appropriate. Yes, mine is a position of huge responsibility, not to mention discretion. People will tell me all their troubles if they get half a chance. You'd never believe some of the things I know about folks in this town. But I think I've written enough for one day.

We are grateful to John Salinsky for these extracts from Norman Gland's diary.

DOI: 10.3399/bjgp08X342101 